\title{
Identification of the distinct promoters for the two transcripts of apoptosis related protein 3 and their transcriptional regulation by NFAT and NF $\kappa$ B
}

Guodong Yang $\cdot$ Fang Yu · Haiyan Fu · Fan Lu •

Bo Huang • Liyuan Bai · Zhongliang Zhao •

Libo Yao - Zifan Lu

Published online: 25 August 2007

(C) Springer Science+Business Media, LLC 2007

Erratum to: Mol Cell Biochem (2007) 302:187-194

DOI 10.1007/s11010-007-9440-7

The name and e-mail address of corresponding author $\mathrm{Lu}$ has to be:

Z. Lu

e-mail: zifan_lu@yahoo.com.cn

The online version of the original article can be found under doi: 10.1007/s11010-007-9440-7.

G. Yang - F. Yu - H. Fu - F. Lu - B. Huang - L. Bai - Z. Zhao · L. Yao $(\square) \cdot \mathrm{Z}$. Lu $(\square)$

Department of Biochemistry and Molecular Biology, State Key

Lab of Cancer Biology, Fourth Military Medical University,

Xi' an 710032, P.R. China

e-mail: bioyao@fmmu.edu.cn

Z. $\mathrm{Lu}$

e-mail: zifan_lu@yahoo.com.cn 